\title{
Social Enterprise and Taxation Policy: A Systematic Literature Review
}

\author{
Mohd Rizal Palil $^{\mathrm{a}, 1, *}$, Ida Suriya Ismail ${ }^{\mathrm{b}, 2}$, Nor Hazila Mohd Zain ${ }^{\mathrm{c}, 2}$, M.A. Anwar Abu Bakar ${ }^{\mathrm{d}, 2}$ \\ ${ }^{a}$ Faculty Economics and Management, Universiti Kebangsaan Malaysia, 43600 Bangi, Selangor, Malaysia \\ ${ }^{b}$ Faculty of Accountancy, Universiti Teknologi MARA, Selangor, Malaysia \\ ${ }^{c}$ Faculty of Business, Information and Human Sciences, Infrastructure University Kuala Lumpur, Selangor, Malaysia \\ ${ }^{\mathrm{d}}$ Faculty of Business, Economics \& Accountancy, University of Malaysia, Sabah, Malaysia \\ ${ }^{1}$ mr_palil@ukm.edu.my *; ${ }^{2}$ idasu634@uitm.edu.my; ${ }^{3}$ norhazila@iukl.edu.my; ${ }^{4}$ allif@ums.edu.my \\ * corresponding author
}

ARTICLE INFO

Article history

Received: February 5, 2021

Revised: September 10, 2021

Accepted: October 10, 2021

\section{Keywords}

Social Business;

Social Enterprises;

Social Entrepreneurship;

Tax Incentive;

Tax Schemes;

\section{ABSTRACT}

Malaysia is likely to introduce new laws on social enterprises of taxation. However, the important questions are whether the said laws are adequate. This study explores previous research on social enterprises and taxation to gain a further understanding through a systematic literature review on social enterprises and taxation from the Malaysian perspective. This is normative legal research. The data was gathered through library research which consisted of numerous publications. This study concludes that tax and social enterprises, perhaps due to the different economic structures in each country, result in taxation being slightly discussed by previous scholars. Nevertheless, we clearly define social enterprises from different perspectives, including the characteristics present in social enterprises. Moreover, the perspective regarding tax relief for social enterprises in Malaysia has been highlighted. Although Malaysia has introduced a new policy to support its social enterprises with Social Enterprise Accreditation, a more significant regulatory or tax incentives approach is needed to support social enterprises in Malaysia.

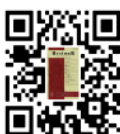

This is an open access article under the CC-BY 4.0 license.

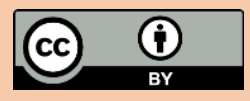

\section{Introduction}

Social enterprises (SEs) have increasingly attracted the attention of scholars from different disciplines and regions in the discussions of theory and practice, financing perspective, typology, and sustainability (Akbulaev et al., 2019; Baskaran et al., 2019; Erpf et al., 2019; Popkova \& Sergi 2019; Samsuddin et al., 2021). Nowadays, SEs are gaining further interest and have been recognized across the world as an alternative approach to achieve social well-being among people in a community. In general, the goal of SEs has expanded beyond traditional businesses - the motive is not only to generate income but also to combat social problems and promote the well-being of the country (Radzi et al., 2021). In this view, the role of SEs is to accommodate needs that the government sector is unable to cover, such as poverty, education, environment, and unemployment.

Basically, the corporation in the capitalist system has two extreme forms. Corporations can be viewed as profit-maximizing enterprises whose goal is to produce shareholder value; the other is nonprofit organizations that exist to achieve social goals (Yunus et al., 2010). From this perspective, SEs are innovative organizations that combine profit-driven and social mechanisms in which the 
profit is directed mainly to the development of such organizations or to public affairs. This agenda makes SEs different from organizations in the private sector that prioritize social change over profit maximization. Although SEs and ordinary businesses (for-profit businesses) have different business objectives, these two entities have similarities in terms of business models and the challenges that must be overcome to compete with other businesses. Given that SEs prioritize social missions, their profitability is usually lower than that of traditional businesses. Consequently, these phenomena create potential barriers for SEs to access financing opportunities from private investors (Yunus et al., 2010).

From the Malaysian perspective, the number (growth) of SEs may not be as great as that of ordinary businesses, as SEs may not receive special treatment for tax purposes. Due to the similarity with profit organizations in terms of business models, these SEs are also subject to income tax by the government. Based on Income Tax Act 1967 in Malaysia, the treatment of SEs is no different from other business entities. It turns SEs into less attractive business models in terms of being profitoriented. The absence of special tax incentives to SEs may discourage social fighters from forming businesses on a social basis. According to Subačienè et al., (2019), government support is important and significant for SEs, as it plays an important role in the growth of SE operations. Ye (2021) noted that an enabling legal framework is required for the sustainable and healthy growth of SEs.

Tax incentives for SEs are one of the most critical issues that should be further studied in detail. Although the number of academic articles on the concept and development of SEs is increasing, research related to their taxation has not been sufficiently discussed. The discussion on the tax treatment of SEs is probably difficult due to the similarity with ordinary enterprises that it is less attractive to scholars. Therefore, we attempt to examine the literature on SEs and taxation that has been discussed in previous studies. Following the systematic process and selected criteria, which are defined by the authors, has reduced the initially listed 36,936 articles to only 20 most relevant articles for extracting and conducting further analysis. Many articles have been removed due to particular reasons that we have determined during Stage 3, which is the eligibility process. Due to the limitation of the study in the context of taxation and SEs as the main topics, the authors have at least included articles that are slightly discussed from a tax perspective. The selected time frame must have been the reason why only a few articles are left. Supposedly, we can extend the publishing year to gather additional relevant articles. However, considering that the analysis process is time-consuming, we must focus on the five-year period. The rest of the articles selected are based on the general topic related to SEs for use in the discussion.

They are various academic articles have been selected throughout the given period (2017-2021). A few criteria and features that have been most debated in the last five years are identified and categorized into research themes on the basis of the main purpose of the present study. In our findings, eleven themes have been discussed: Development, Tax Policy, Sustainability, Legal Framework, Public Policy, Financing, Social Enterprise Ecosystem, Typology, Market-oriented, Ideology, and Business Model. As presented in most previous studies commonly focused on development (Doherty \& Kittipanya-ngam 2021; García-Jurado et al., 2021; Popkova \& Sergi 2019), SEs sustainability (Ketprapakorn \& Kantabutra 2019; Mahfuz Ashraf et al., 2019; Samsuddin et al., 2021), and legal framework (Kadir et al., 2019; Nizam et al., 2017; Ye 2021). Two studies concentrated on tax policies in SEs (Killian \& O'Regan 2019; Radzi et al., 2021), two papers focused on public policy (Choi et al. 2020; Choi \& Park 2020), and two other studies were conducted from the financing perspective (Akbulaev et al., 2019; Subačienė et al., 2019). Most remaining papers concentrated on typology to analyze the definitions of SEs (Erpf et al., 2019). One study focused on ideology between two schools of thought on SEs in Malaysia (Harun et al., 2017). Another research (Baskaran et al., 2019) explored SEs ecosystem in Malaysia. One study analyzed market-oriented SEs from a social welfare perspective (Gidron \& Monnickendam-givon 2017). Last, one research work (Akter et al., 2020) paid attention to SEs business models for empowerment and economic growth in emerging economies.

In the past few years (2019 and 2020), a growing number of academics have turned their attention to sustainability research; legal framework; and SEs development, particularly in the Asian region (Abdul Kadir et al., 2019; Doherty \& Kittipanya-ngam 2021; García-Jurado et al., 2021; Ketprapakorn \& Kantabutra 2019; Nizam et al., 2017; Popkova \& Sergi 2019; Samsuddin et al., 
2021; Ye 2021). The reason may be that SEs are still in the developing stage in the Asian region compared with those in developed countries. Moreover, only a relatively small body of literature is concerned with taxation and SEs. Here, studies on taxes are not often discussed from the SEs perspectives among scholars. Based on our findings, two studies specifically discuss taxation and SEs, namely, those by Radzi et al., (2021) and Killian and O'Regan (2019). Radzi et al., (2021) attempted to discover the possibility of a new tax treatment that can be implemented on SEs in Malaysia. Meanwhile, Killian and O'Regan (2019) reviewed tax policies by highlighting the significance and applicability of tax considerations to the aim of achieving effective sustainable development and social value. We also find one study (Subačienè et al., 2019) that discussed taxation. However, this research evaluated the impacts of state support and corporate income exemption for SEs on the state budget.

In this context, the present study provides an overview from the SEs and taxation perspectives. A systematic literature review (SLR) is conducted with the goal of consolidating knowledge, clarifying main topics that are always being discussed by scholars, and identifying any gaps in current research to suggest areas for further investigation. The purpose is to review recent research with the aim of obtaining further understanding and discussing the topic in a systematic way. This review also examines the concept of SEs by finding its definitions and characteristics on the basis of previous research. In addition, SEs and taxation from the Malaysian perspective are highlighted. The paper is organized as follows: the first section explains the purposes of the study. The second section presents the methodology used. The third section discusses the findings of selected articles by summarizing their purposes, contributions, and themes. The fourth section defines SEs and provides discussions from the SEs and taxation perspectives in Malaysia. The last section summarizes the findings and limitations, including some suggestions for future research.

This study aims to review studies on SEs and taxation by focusing on articles published from 2017 to 2021. The main purpose is to consolidate the knowledge of different scholars and perspectives on SEs to gain an improved understanding of SEs definitions and taxation views. We also aim to shed light on the issues of taxation and SEs from the Malaysian perspective. From the analysis of the SLR, we find various research topics that have been discussed repeatedly for the past five years. Specifically, 11 themes of studies have been discussed by previous scholars in the context of SEs. In general, the most common topics continuously discussed are SEs development, sustainability, and legal framework. Unfortunately, research on the tax perspectives of SEs is limited. The reason may be due to the selected time frame (five years), which only covers a small number of studies. Certain limitations are observed in the SLR, such as the fact that the selected articles only focus on a few databases. Most contents are also retrieved between 2017 and 2021. Therefore, the number of articles about tax perspectives is limited. Most researchers rarely discuss taxation and SEs, thus, studies on both topics can be conducted in the future by referring to another country and interviewing policymaker to gain new insights. Furthermore, the literature review can be expanded in terms of database searches and publication periods to gather additional valid research articles about taxation.

\section{Research Methods}

An SLR is conducted with the goal of exploring and understanding the trends and gaps in the scientific literature related to SEs and taxation. A systematic review is a process that examines a clearly stated issue by using systematic and explicit techniques to find, select, and critically appraise relevant literature and to gather and analyze data from the studies included in the review (Moher et al., 2009). According to Zawacki-Richter et al., (2020), this approach is used to determine existing findings, such as about a phenomenon, an issue or a topic; and for primary research to offer answers to questions for which previous studies do not provide clear and comprehensive answers. Therefore, this method is presented to analyze and interpret previous studies to address research objectives. In general, publishing standards must provide authors with reliable and relevant information that enables them to review and examine the quality and rigor of reviews. Therefore, we use the Preferred Reporting Items for Systematic Review and Meta-Analyses (PRISMA) statement as a guideline in conducting this review paper. According to Moher et al., (2009), PRISMA statement not only helps authors improve the reporting of systematic review but also can be used to report 
systematic reviews of other types of studies, especially intervention evaluations, and for the critical appraisal of published systematic reviews. Thus, PRISMA assists authors in collecting all materials that meet predefined eligibility criteria to answer particular research questions and enable researchers to use explicit and systematic approaches to reduce bias. Herwegen and Simms (2020) argued that research protocol is needed to ensure that researchers strictly follow an outlined plan in a systematic review.

The study review procedures are followed using two major databases: Web of Science (WOS) and Scopus. Both databases comprise various journal articles that cover multidisciplinary studies, including those on SEs and taxation. Apart from providing high-quality research papers, these database collections (specifically WOS) provide cover-to-cover indexing back to the 1900s across the world's highest-quality and most impactful publications to researchers. However, no database, including WOS and Scopus, is comprehensive and perfect in providing a complete set of published materials needed (Xiao \& Watson 2019). Therefore, we explore other databases to improve the search process because collecting relevant information, especially about taxation, is difficult. Xiao and Watson (2019) and Younger (2010) added that researchers are suggested to use more than one database (multiple) to increase the possibility of discovering relevant articles. As a searching strategy, we thus exert manual searching efforts on data sources provided by library institutions, such as Taylor \& Francis, Springer, and Google Scholar, in collecting additional reliable articles.

\section{Results and Discussion}

\subsection{Social Enterprise: A Systematic Literature Review}

According to Erpf et al., (2019), SEs have various definitions due to the lack of rigorous methods in discussing such definitions, including different areas of treatments and perspectives. Therefore, they attempted to highlight the typologies for SEs with an empirically validated taxonomy. Akbulaev et al., (2019) described that the complexity of defining SEs arises from the multidimensionality of entrepreneurship, which considers a wide range of tasks and existing characteristics. Akbulaev et al., (2019) also noted that the nature of SEs can be further understood by reading the three main approaches to their definitions, which are (1) SEs are entrepreneurial activities of nonprofit organizations with the aim of achieving their statutory objectives; (2) SEs are related to the fact that their social impact on entrepreneurial activities is more important than financial efficiency, as opposed to simple businesses; and (3) SEs are innovative entrepreneurial activities that bring about social change in societies and communities.

Dees and Anderson (2006) emphasized that the best way of framing SEs is based on two dominant schools of practice and thought, namely, the social enterprise school and the social innovation school. They argued that SEs are essentially referred to as "earned-income" to serve social missions; meanwhile, the social innovation school is focused on establishing new and improved ways to address social problems or meet social needs. Dees and Anderson (2006) added that no clear answer exists to the question of which school should claim the term "social entrepreneurship." Therefore, understanding the concept of SEs on the basis of these schools of practice is important. A further explanation regarding this concept can be seen in Harun et al., (2017) who discussed two different schools of thought from Malaysian SEs perspectives, which are known as social innovation and social business.

Definitions of SEs have evolved on the basis of various direct activities that complicate their nature and distinguish them from nonprofit organizations and for-profit businesses. According to Abdul Kadir et al., (2019), SEs are business-oriented organizations established to advance social causes in a financially sustainable manner. SEs can also be legally registered organizations whose activities are not for profit but aim to solve social problems (Akbulaev et al., 2019). Popkova and Sergi (2019) argued that SEs are particular types of businesses whose aim is to make a public (in the form of solving social problems) rather than a private (commercial) profit through the implementation of socially significant projects.

In general, the characteristics of SEs are different in nonprofit organizations and for-profit firms in that they are market-oriented (generate revenue) while pursuing social goals rather than profit alone (Choi \& Park 2020). They are a combination of the profit-making components of for-profit 
businesses with the social values and missions of nonprofit organizations (Kadir et al., 2019; Choi et al. 2020). Popkova and Sergi (2019) said that SEs have three obligatory characteristics: (1) They must have the secondary character of own (commercial) and the primary character of public (noncommercial) interest, (2) the absence of profit expectation, and (3) the implementation of a socially important initiative. Akbulaev et al., (2019) also stated that five aspects of criteria must be considered to define themselves as SEs: social impact, innovativeness, profit and financial sustainability, democratic management, and the ability to reinvest profit in businesses or for social purposes.

From the definitions of SEs, we clearly find that their role is not only to solve and achieve social goals but also to be sustainable in terms of profitability and finances to compete with other conventional businesses (Akbulaev et al., 2019). SEs seem like hybrid organizations established for a social purpose and use a for-profit business model to generate the financial resources needed to support their social missions (Subačienè et al., 2019). Choi et al., (2020) argued that SEs are distinct from social entrepreneurship, whereby SEs are strongly associated with market-oriented organizational activities with a social purpose, whereas social entrepreneurship focuses on the ability of individual social entrepreneurs to use market-oriented ideas and creativity to run their organizations. As stated by Akter et al. (2020), social entrepreneurship is the subset of SEs and social businesses.

Meanwhile, Ashraf et al., (2019) attempted to distinguish among SEs, social businesses, and NGOs. From their analysis of the literature review, they clearly mentioned that SEs and social business missions solve specific social problems independently and sustainably through innovative solutions. In terms of business characteristics, SEs are social benefit-maximizing organizations that perform either non-dividend or dividend-taking business. Meanwhile, the social business aspect pays further attention to the non-dividend concept. NGOs specifically solve social or humanitarian or environmental problems, and the funds are commonly arranged by donations or grants by the government.

From the above explanation, diverse definitions demonstrate the broad breadth of SEs. Many scholars have extensively investigated SEs and distinguished them among SEs, social entrepreneurs, and NGOs (Akter et al., 2020; Choi et al., 2020; Ashraf et al., 2019). Although many scholars have attempted to identify a few features and various definitions of social entrepreneurship and SEs, they often increase the feeling of confusion among researchers (Defourny \& Nyssens 2017). As mentioned in the literature review, SEs can be considered nonprofit enterprises, social purpose businesses or income-generating enterprises established to assist poor and disadvantaged populations or to create economic opportunities (Kadir \& Mhd Sarif 2016). They are business entities that have social missions through their business approach and do not primarily seek profit. However, SEs must make a profit similar to other companies to exist and function in the market.

\subsection{Social Enterprise and Taxation Policy: Malaysian Perspective}

In the context of Malaysia, the idea of SEs may still be quite new and is still in the growing phase. MaGIC (2015) reported that 100 SEs operate in the areas of education, poverty, rural development, environmental sustainability, and employment for the marginalized and at-risk youth. Currently, the total number of SEs in Malaysia is approximately 20,000, including those on a voluntary basis; and 64\% are based in Klang Valley. Although the number of SEs in Malaysia has actively increased in addressing social issues, many barriers remain that make SEs challenging to grow their businesses and increase their impact on society. Samsuddin et al., (2021) revealed that based on a report from MaGIC (2015), most SEs in Malaysia remain financially immature, underperforming and unable to survive.

Moreover, several challenges must be solved, including the lack of legal recognition and policy structure, lack of access to quality human capital, lack of access to sizeable financial capital, and lack of support to grow. Furthermore, the most significant hurdles encountered are the lack of legal definition and recognition of SEs as business entities in Malaysia (UN.ESCAP 2019). As a result, these issues create confusion for many social entrepreneurs operating under various legal forms, preventing them from engaging in major commercial activities or obtaining tax and financial benefits for nonprofit organizations (Kadir \& Mhd Sarif 2016; UN.ESCAP 2019). 
Although a general reference exists in Malaysia in the form of the Malaysian Social Enterprise Blueprint 2015-2018, Kadir et al., (2019) argued that neither standard guidelines for implementation nor conventions for the public had been established and documented. Therefore, this issue leads to disadvantages for newcomers who want to start SEs, as no legal framework can be used as a reference. Nevertheless, Radzi et al., (2021) highlighted that in 2019, Malaysia launched the Guidelines for Social Enterprise Accreditation (SEA), which is a national certification that recognizes legitimate SEs. The SEA intends to certify the status of SEs to help the SEs sector access great support and opportunities to grow. In the guidelines for SE.A, one of the criteria is that SEs must be financially sustainable, that is, generating more than half $(50 \%)$ of their total annual turnover (by selling goods or services to customers, as opposed to donations or grants). SEs must also proactively create positive social and environmental impacts.

Despite having new regulations and accreditations toward SEs in Malaysia, no privilege exists in terms of tax exemption on SEs. Furthermore, tax deduction incentives are for those who contribute (individual and corporate donors) to SEs ("MaGIC Central" n.d.; Radzi et al., 2021). The reason is that SEs in Malaysia are registered under the Companies Act 2016 Section 45 as companies limited by guarantee or as companies limited by shares. Therefore, SEs do not have any special treatment in taxation exemption and are treated the same as other conventional businesses, even though they (SEs) are different from ordinary businesses in terms of social missions. Kadir et al., (2019) stated that no legal provision allows businesses with social missions to automatically be eligible for tax relief from the Inland Revenue Board without additional procedure or declaration. Unless they are charitable entities registered under the Societies Act 1966 (Section 2) that are entitled to tax exemption under Section 44 (6) Income Tax Act 2015 (Kadir et al., 2019; Radzi et al., 2021).

According to Radzi et al., (2021), SEs are different from charitable organizations. The Income Tax Act of 1967 also has a differential tax treatment for corporate entities and charitable organizations. With regard to SEs as business entities that demonstrate for-profit and nonprofit in their activities, they may not be eligible to register their companies under the Societies Act 1966 (Kadir et al., 2019). Meanwhile, if organizations are registered under the Societies Act 1966, they are strictly prohibited from actively participating in commercial businesses. Therefore, SEs in Malaysia have no uniqueness in creating social impact from other companies. Moreover, achieving tax relief under social missions is difficult. In this situation, the absence of tax relief for SEs may discourage them from growing and expanding their scale to the highest stage.

In general, enjoying full tax exemption in Malaysia is applicable to companies registered under the Company Limited by Guarantee of the Companies Act 2016 and even to organizations registered under the Societies Act 1966; however, strict requirements must be followed (Radzi et al., 2021). To apply for tax exemption, SEs and other organizations must be founded continuously and not for profit-orientation purposes. The contribution extends to all Malaysians regardless of their races, beliefs, and political understanding. Therefore, SEs are still subject to taxation on any income that is unrelated to nonprofit activities. Meanwhile, no special tax relief is given to SEs, but they can still achieve any tax exemption under a certain situation, as given under the Income Tax Act.

Basically, the missions of SEs are diverse; most of these missions do not meet the specific purpose rules on charity regulations. Some SEs may operate from the charity (non-profit) and forprofit spectra, which have predominant social purposes. Until now, from the Malaysian perspective, recent developments have yet indicated that SEs are legislated under a new legal framework (Kadir et al., 2019). According to Killian and O'Regan (2019), SEs pose specific challenges to tax systems, and many jurisdictions have not addressed the question of how to foster hybrids in their tax system. Therefore, developing new special tax schemes for Malaysian SEs is not an easy task, but it can be in the future. Hence, Radzi et al., (2021) suggested that the Malaysia Income Tax Act 1967 needs an amendment to have an effect on SE economics.

Nonetheless, if looking at developed countries, such as the United Kingdom, South Korea, and the United Stated, they have established their own mechanism and legal form regarding SEs. These countries are the best references to use in forming the publicness of SEs. According to Choi et al., (2020), these countries can be considered to have mature policy frameworks and have developed different approaches to the designs of SEs. Other countries also support the operation of SEs by providing tax exemption; for example, South Korea under the Special Tax Treatment Control Act 
2014 (Kadir et al., 2019). Doh (2020) revealed that certified SEs in South Korea could receive many benefits, such as management and training support, facility cost support, priority purchase for public agencies, tax exemption, social insurance premium assistance, funding for social-service-providing enterprises, employment liability exemption, and tax reduction for affiliated companies.

\section{Conclusion}

In Malaysia, SEs are defined as business entities registered under any written law in the country that proactively creates positive social or environmental impact in a way that is financially sustainable. In general, SEs can be regarded as one of the innovative solutions to fill the gap in the government sector, which is unable to provide comprehensive services to its citizens due to resource constraints. Nowadays, these business entities exist around the world in every economic sector and are involved in a wide range of activities from social and welfare, environment, health, tourism, and education services. Although SEs have been proven to play an important role in addressing social problems and have a positive impact on the socio-economic development in Malaysia, reaping the benefits from SEs requires long-term government support for growth and financial sustainability to bring the impact to the community and even to the economic level. Many countries have their own mechanism and policy to support and provide incentives to increase the development of their SEs, such as the UK, the USA, and South Korea. Recently, Malaysia is taking a new initiative by introducing the Guidelines for SEA to certify the status of SEs and thus help them access further support and opportunities to grow. However, this initiative seems insufficient to support social entrepreneurs, especially in terms of tax relief. Introducing tax exemption (in certain periods) for SEs in Malaysia can reduce the burden and perhaps can provide growth effectively. With the current COVID-19 situation, the role of SEs is considered essential to assist the government in ensuring socio-economic development by providing job opportunities or improving community health.

\section{References}

Akbulaev, N., Aliyev, Y. \& Ahmadov, T. 2019. Research Models for Financing Social Business: Theory and Practice. Heliyon 5(5): e01599. https://doi.org/10.1016/j.heliyon.2019.e01599

Akter, S., Jamal, N., Ashraf, M.M., McCarthy, G. \& Varsha, P.S. 2020. The Rise of the Social Business in Emerging Economies: A New Paradigm of Development. Journal of Social Entrepreneurship 11(3): 282-299. https://doi.org/10.1080/19420676.2019.1640772.

Baskaran, A., Tang, M., Thiruchelvam, K., Shahabudin, S.M. \& Chan, T.S.Y. 2019. Social Entrepreneurship and Inclusive Growth: Attributes, Perceptions and Roles of Business Incubators and Intermediaries in Malaysia. Science, Technology and Society 24(3): 486-506. https://doi.org/10.1177\%2F0971721819873186

Choi, D., Berry, F.S. \& Ghadimi, A. 2020. Policy Design and Achieving Social Outcomes: A Comparative Analysis of Social Enterprise Policy. Public Administration Review 80(3): 494505. https://doi.org/10.1111/puar.13111

Choi, D. \& Park, J. 2020. Local Government as a Catalyst for Promoting Social Enterprise. Public Management Review 23(5): 665-686. https://doi.org/10.1080/14719037.2020.1865436

Dees, J.G. \& Anderson, B.B. 2006. Framing a Theory of Social Entrepreneurship: Building on Two Schools of Practice and Thought. Research on Social Entrepreneurship 39-66. Google Scholar

Defourny, J. \& Nyssens, M. 2017. Fundamentals for an International Typology of Social Enterprise Models. VOLUNTAS: International Journal of Voluntary and Nonprofit Organizations 28(6): 2469-2497. https://doi.org/10.1007/s11266-017-9884-7

Doh, S. 2020. Social Entrepreneurship and Regional Economic Development: The Case of Social Enterprise in South Korea. Sustainability 12(8843): 1-20. https://doi.org/10.3390/su12218843 
Doherty, B. \& Kittipanya-Ngam, P. 2021. The Emergence and Contested Growth of Social Enterprise in Thailand. Journal of Asian Public Policy 14(2): 251-271. https://doi.org/10.1080/17516234.2020.1777628.

Erpf, P., Tekula, R. \& Neuenschwander, J. 2019. Clustering Social Enterprises: An Empirically Validated Taxonomy. Social Enterprise Journal 15(3): 397-420. https://doi.org/10.1108/sej-12-2018-0081

García-Jurado, A., Pérez-Barea, J.J. \& Nova, R.J. 2021. A New Approach to Social Entrepreneurship : A Systematic Review and Meta-Analysis. Sustainability 13(2754): 1-16. https://doi.org/10.3390/su13052754

Gidron, B. \& Monnickendam-Givon, Y. 2017. A Social Welfare Perspective of MarketOriented Social Enterprises. International Journal of Social Welfare 26(2): 127-140. https://doi.org/10.1111/ijsw.12232

Harun, N., Abd Ghadas, Z.A. \& Md Radzi, M.S.N. 2017. School of Thought of Social Enterprises : An Appraisal of Social Enterprise in Malaysia. World Applied Sciences Journal 35(9): 1804-1807. Google Scholar

Herwegen Van, J. \& Simms, V. 2020. Research in Developmental Disabilities Mathematical Development in Williams Syndrome: A Systematic Review. Research in Developmental Disabilities 100(October 2019): 103609. https://doi.org/10.1016/j.ridd.2020.103609.

Kadir, M.A.B.A., \& Mhd Sarif, S. 2016. Social Entrepreneurship, Social Entrepreneur and Social Enterprise: A Review of Concepts, Definitions and Development in Malaysia. Journal of Emerging Economies and Islamic Research 4(2): 51-66. https://doi.org/10.24191/jeeir.v4i2.9086

Kadir, M.A.B.A., Zainudin, A.J., Jarun, U.S., Mohamad, N.A. \& Harun, N.H.A.C. 2019. Malaysian Social Enterprise Blueprint 2015-2018: What's next? ASEAN Entrepreneurship Journal 5(2): 1-7. Google Scholar

Ketprapakorn, N. \& Kantabutra, S. 2019. Sustainable Social Enterprise Model: Relationships and Consequences. Sustainability 11(14): 1-39. https://doi.org/10.3390/su11143772

Killian, S. \& O'Regan, P. 2019. Taxation and Social Enterprise: Constraint or Incentive for the Common Good. Journal of Social Entrepreneurship 10(1): 1-18. https://doi.org/10.1080/19420676.2018.1517103.

MaGIC Central. (t.th.). https://central.mymagic.my/sea [26 August 2021].

MaGIC, M.G.I. and C.C. 2015. Unleashing The Power of Social Entrepreneurship: Malaysian Social Entreprise Blueprint 2015-2018. Cyberjaya, Malaysia.

Mahfuz Ashraf, M., Razzaque, M.A., Liaw, S.T., Ray, P.K. \& Hasan, M.R. 2019. Social Business as an Entrepreneurship Model in Emerging Economy: Systematic Review and Case Study. Management Decision 57(5): 1145-1161. https://doi.org/10.1108/md-04-2017-0343

Moher, D., Liberati, A., Tetzlaff, J., Altman, D.G., Altman, D., Antes, G., Atkins, D., Barbour, V., Barrowman, N., Berlin, J.A., Clark, J., Clarke, M., Cook, D., D’Amico, R., Deeks, J.J., Devereaux, P.J., Dickersin, K., Egger, M., Ernst, E., Gøtzsche, P.C., Grimshaw, J., Guyatt, G., Higgins, J., Ioannidis, J.P.A., Kleijnen, J., Lang, T., Magrini, N., McNamee, D., Moja, L., Mulrow, C., Napoli, M., Oxman, A., Pham, B., Rennie, D., Sampson, M., Schulz, K.F., Shekelle, P.G., Tovey, D. \& Tugwell, P. 2009. Preferred Reporting Items for Systematic Reviews and Meta-Analyses: The PRISMA Statement. PLOS Medicine 6(7). https://doi.org/10.3736/jcim20090918

Nizam, S.M., Bidin, A. \& Murshamshul, M.K. 2017. Public Interest Corporation: A New Business Platform for Social Entrepreneurship in Malaysia. Pertanika Journal of Social Science and Humanities 25(October): 129-134. Google Scholar 
Popkova, E.G. \& Sergi, B.S. 2019. Social entrepreneurship in Russia and Asia: further development trends and prospects. On the Horizon 28(1): 9-21. https://doi.org/10.1108/oth09-2019-0065

Radzi, S.N.M., Rahim, S.A., Zainol, N.R., Ariff, Z., Mansyar, M. \& Daud, R.R.R. 2021. Special Tax Scheme for Malaysia's Social Enterprise: An Incentive for Public Good. Lecture Notes in Networks and Systems 194 LNNS(Light 2006): 1032-1041. https://doi.org/10.1007/978-3030-69221-6_79

Samsuddin, M.E., Salleh, M.F., Ahmad, A. \& Amir, A.M. 2021. Influence of Stakeholders on Sustainability of Social Enterprises: A Critical Review Study. International Journal of Business and Technopreneurship 11(1): 51-60. Google Scholar

Subačienè, R., Budrionyte, R., Mačerinskienè, A. \& Tamulevičienė, D. 2019. Social Enterprises: Evaluation of the Impact of State Support and Corporate Income Exemptions on the State Budget of Lithuania. Entrepreneurship and Sustainability Issues 6(3): 1156-1171. https://doi.org/10.9770/jesi.2019.6.3(7)

UN.ESCAP. 2019. The State of Social Enterprise in Malaysia 2018. https://hdl.handle.net/20.500.12870/2885.

Xiao, Y. \& Watson, M. 2019. Guidance on Conducting a Systematic Literature Review. Journal of Planning Education and Research 39(1): 93-112. https://doi.org/10.1177/0739456X17723971.

Ye, M. 2021. Building an Enabling Legal Environment: Laws and Policies on Social Enterprises in China. Journal of Asian Public Policy 14(2): 182-199. https://doi.org/10.1080/17516234.2020.1824263.

Younger, P. 2010. Using Google Scholar to conduct a Literature Search. Nursing Standard 24(45): 40-46. Google Scholar

Yunus, M., Moingeon, B. \& Lehmann-Ortega, L. 2010. Building Social Business Models: Lessons from the Grameen Experience. Long Range Planning 43: 308-325. https://doi.org/10.1016/j.lrp.2009.12.005

Zawacki-Richter, O., Kerres, M., Bedenlier, S., Bond, M. \& Buntines, K. 2020. Systematic Reviews in Educational Research: Methodology, Perspectives and Application. Springer Nature. https://doi.org/10.1007/978-3-658-27602-7 